1. MBBS, MPhil (Pharmacology) Associate Professor Hitec-ims Taxila.

2. MBBS, MPhil (Pharmacology) Associate Professor FUMC Islamabad.

3. MBBS, M.Phil (Pharmacology) Assistant Professor

Northwest School of Medicine Peshawar.

4. MBBS, M.Phil (Pharmacology) Associate Professor FUMC Islamabad.

5. MBBS, M.Phil (Pharmacology) Assistant Professor

Fazaia Medical College, Islamabad.

6. MBBS, M.Phil (Pharmacology) Assistant Professor

Margalla Institute of Health Sciences, Rawalpindi.

Correspondence Address: Dr. Naila Abrar

Department of Pharmacology \&

Therapeutics

HITEC Institute of Medical Sciences,

Taxila.

nylahmed@hotmail.com

Article received on:

19/08/2019

Accepted for publication: 25/01/2020

\section{NITRIC OXIDE PATHWAY-MEDIATED RELAXANT EFFECT OF PPAR (PERACISOME PROLIFERATOR ACTIVATED RECEPTOR)-GAMMA AGONIST IN THE GUINEA-PIG ISOLATED TRACHEA.}

\begin{abstract}
Naila Abrar ${ }^{1}$, Ayesha Janjua ${ }^{2}$, Sarwat Jahan ${ }^{3}$, Zarafshan Badar ${ }^{4}$, Asma Khan ${ }^{5}$, Fatima Qasim ${ }^{6}$
ABSTRACT... Objectives: This study focuses on the role of the mediator of smooth muscles i.e. nitric oxide in the effect of rosiglitazone on the relaxation of contractions in guinea pig trachea induced by histamine. Study Design: Experimental Study. Setting: Department of Pharmacology, Army Medical College, Rawalpindi. Period: $1^{\text {st }}$ December 2018 till $14^{\text {th }}$ December 2018. Material \& Methods: The activity of the trachealis mucle of the guinea pigs was noted by the use of oxygenated solution of Krebs-Henseleit. The contractions were noted with rosiglitazone alone as well as in presence of an ester of L-nitro-arginine-methyl, which can antagonize the activity of NO. The activity was measured by the use of an isometric force displacement transducer and was then recorded on an oscillograph with four channels. Results: The ester L-nitro-arginine-methyl was able to reduce the relaxant effect of rosiglitazone on the contractions induced by histamine. Conclusion: It can be suggested that the relaxation induced by rosiglitazone is mediated in part through NO.
\end{abstract}

Key words: $\quad$ Nitric Oxide (NO), PPAR Agonist, Tracheal Relaxation.

Article Citation: Abrar N, Janjua A, Jahan S, Badar Z, Khan A, Qasim F. Nitric oxide pathwaymediated relaxant effect of PPAR (Peracisome proliferator activated receptor)-gamma agonist in the guinea-pig isolated trachea. Professional Med J 2020; 27(9):1855-1861. DOI: 10.29309/TPMJ/2020.27.09.4054

\section{INTRODUCTION}

The enormous increase in the prevalence of chronic obstructive pulmonary disease and asthma ${ }^{1}$, diseases characterized by hyper reactivity of bronchi and bronchospasm, has attracted considerable attention to the development of unconventional therapeutic options against representative diseases. Thiazolidinediones are valuable agents used as a treatment option in patients suffering from type II diabetes mellitus (T2DM) as well as metabolic syndrome. ${ }^{2,3}$ The therapeutic benefits of TZDs expand beyond their use in diabetes. Their importance in various other ailments including Alzheimer's disease, pancreatitis and inflammatory airway diseases has also been studied. 4,5,6,7,8 Several studies show that thiazolidinediones and PPAR agonists have beneficial effects in models of asthmatics as well as chronic obstructive pulmonary disease (COPD) leading to the reduction in the responsiveness and hyper reactivity of airways. ${ }^{9,10}$ They activate various members of the steroid aka nuclear receptor superfamily, importantly PPAR- $\gamma$. The activation of a number of genes that lead to inflammation is suppressed by the PPAR-y ligands and rosiglitazone, hence exhibiting themselves as potent anti-inflammatory agents. ${ }^{11,12}$ It has been acknowledged that PPAR-y ligands such as TZDs have a role in cell proliferation and malignancy. ${ }^{13,14}$ PPAR- $\gamma$ is found in the airway passages as well as lungs. The epithelium, airway smooth muscles, as well as the cells of inflammation are responsible for the expression of PPAR-y. ${ }^{15,16}$ As a result of the identification of PPAR- $\gamma$ in lung tissue and cells associated with inflammation in the lungs and airways, the PPAR- $\gamma$ has been studied as a target for interventional study.

PPAR ligands are capable of modulation and remodeling of the airway by decreasing the migration of the airway smooth muscles and production of the matrix. A number of current studies have demonstrated that the PPAR-Y agonists have beneficial effects in models of asthma. ${ }^{17,18,19}$ Airway submucosal and structural cells, show an increased expression of PPARy 
during the inflammatory and remodeling response in asthma. ${ }^{20,21}$ In a pharmacological model, rosiglitazone reversed the pro-asthmatic changes induced by persistent beta 2 receptor activation, thereby, improving the therapeutic index of the agonists of $\beta_{2}$ receptors. ${ }^{22}$ Synergistic interaction between PPAR- $\gamma$ agonists and agonists of the $\beta_{2}$ receptor on bronchial smooth muscle cell proliferation has been observed. ${ }^{23}$ The inflammation as well as the remodeling of the airways induced by ovalbumin (OVA) in a mouse model, were decreased significantly by the intranasal administration of rosiglitazone. The number of the inflammatory cells including the eosinophils and neutrophils were decreased so were the levels of IL-5 and IL-13. In addition there was a decrease in the thickness of the airway smooth muscle layer and reduced deposition of the collagen in the airway. ${ }^{24}$ It has been postulated that rosiglitazone has activity on the airways sparing the parenchyma of the lung since rosiglitazone did not affect the compliance of the lung. This inhibition by rosiglitazone occurred without significant effect on the OVAinduced increase in the inflammatory cells in bronchoalveolar lavage. Therefore, it can be a possibility that rosiglitazone modulates airway hyperreactivity (AHR) by a mechanism that is independent of inflammatory cell recruitment to the airway.

Nitric oxide (NO) is an established regulator of diverse physiologic processes. Its involvement in host defense, neurotransmission, platelet aggregation, gastrointestinal and vascular smooth muscle regulation is all well recognized. $\mathrm{NO}$ has an established role in the tone of the airway smooth muscles. ${ }^{26,27} \mathrm{NO}$ stimulates the mechanisms leading to the relaxation of smooth muscles in the airways. In addition the enzyme, Nitric oxide synthase is found in the airways pointing towards the possible involvement of NO in the pathophysiology of asthma. ${ }^{28}$ Nitric oxide possesses broncho-dilatory property that in part is mediated by the synthesis of s-nitrosothiols (SNOs). ${ }^{29}$ This compound leads to the activation of guanylyl Cyclase which eventually induces bronchial relaxation. ${ }^{30}$ Studies have shown of $\mathrm{NO}$ and related signaling pathways in various effects of PPAR-Yy including the brain and endothelial system. ${ }^{31,32}$ Pioglitazone treatment also significantly increased total enzyme activity of NOS in hypertensive rats. ${ }^{33}$

It is evident that the exact mechanism of the airway relaxant effects of the PPAR- $\gamma$ agonists is not well established. In consideration of the role of No in airways and its association with effects of PPAR- $Y$ elsewhere in the body, we studied the modulation of the smooth muscle relaxation by inhibitors of No in an isolated intact guinea pig trachea that had been treated with rosiglitazone.

\section{MATERIAL \& METHODS}

\section{Guinea pig trachea isolation}

The study was conducted from $1^{\text {st }}$ December

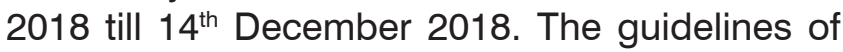
the institutional care of animals were followed. Dunken Hartley guinea pigs $(500-600 \mathrm{~g})$ were killed by cervical dislocation. The chest was opened through an incision in the midline. Through surgery a segment of the cervical trachea measuring $8-10 \mathrm{~mm}$ was taken out intact. The tracheal segment was not manipulated any further and was directly placed in a preoxygenated Kreb's Henseleit solution. The solution had the following composition per 100ml $(\mathrm{mM}): \mathrm{NaCl} 118.2, \mathrm{KCl} 4.7, \mathrm{CaCl}_{2} 2.5, \mathrm{Mg}_{2} \mathrm{SO}_{4}$ 1.2, $\mathrm{NaHCO}_{3} 25, \mathrm{KH}_{2} \mathrm{PO}_{4} 1.3$ and glucose 11.7. A gas mixture of $95 \% \mathrm{O}_{2}$ and $5 \% \mathrm{CO}_{2}$ was bubbled into the solution.

\section{Studies on Isometric Tension}

In order to look for the changes in the muscle tension, the intact segment of the trachea was placed in an organ bath with $50 \mathrm{ml}$ water and Kreb's Henseleit solution maintained at $37^{\circ} \mathrm{C}$, and supplied with oxygen. The strip of the trachea was attached at one end to the the oxygen tube while the other end of it was attached to an isometric force displacement transducer of Harvard model number \& 72-4494. The recordings of the transducer were then recorded through an oscillograph with four channels. Equilibration of the trachea was performed against a passive load weighing 2 grams kept at a temperature of $37^{\circ} \mathrm{C}$ for time duration of $45 \mathrm{~min}$. 


\section{Stimulation by Drugs}

Effect of rosiglitazone on the contraction induced by histamine

Following the equilibration period performed initially, the baseline tension was adjusted by addition of $10^{-3} \mathrm{M}$ histamine. Histamine was washed out from the organ bath once the effect of histamine was recorded to reach a plateau. Then the tension at the baseline was restored by allowing the tissue to relax. Then forth the same experiment was repeated by increasing the histamine concentrations to $10^{-4} \mathrm{M}, 10^{-5} \mathrm{M}, 10^{-6}$ $\mathrm{M}$ and $1 \mathrm{O}^{-7} \mathrm{M}$ randomly. The tissue was allowed to relax for a period of ten minutes between all the concentrations. A concentration response curve was then constructed after calculating the mean values at different concentrations.

Next a fixed dose of $100 \mu \mathrm{M}$ of rosiglitazone was used against which the effect of histamine was noted. Rosiglitazone $100 \mu \mathrm{M}$ was added and was left to be in contact with the tracheal tissue for a period of 15 minutes. Then the contractions produced by histamine were recorded on this tissue. A mean was calculated for the six experiments and a concentration response curve constructed.

\section{Effect of L-NAME on the contractions induced by} histamine and rosiglitazone induced relaxation In an attempt to study the role of endogenous $\mathrm{NO}$ in the contractility of trachea, six experiments were performed. Trachea was first incubated with the NO synthetase inhibitor known as L-NAME in a concentration of $120 \mu \mathrm{M}$. It was then followed by the addition of rosiglitazone and increasing histamine concentrations randomly. A mean was calculated for the six experiments and a concentration response curve constructed.

\section{Statistical Analysis}

The data obtained from the experiments was noted as mean \pm SEM. All the calculations were done using SPSS version 20. The comparative data were presented through the one way ANNOVA along with the Tukey's post hoc test. The percentage of the response as well as the deviation was calculated. A value of $p<0.05$ was taken as significant statistically.

\section{RESULTS}

Action of rosiglitazone on the tissue that had the histamine pre-treatment both in the presence as well as the absence of L-NAME were noted. Statistically significant $(P<0.05)$ difference was found when the mean values shown with the differing concentrations of histamine ranging from $10^{-7}$ to $10^{-3} \mathrm{M}$ were compared first to the group that had the pretreatment with rosiglitazone and then to the group that had the pretreatment with both L-NAME as well as rosiglitazone. The mean deviation was calculated to be 25.34 percent.

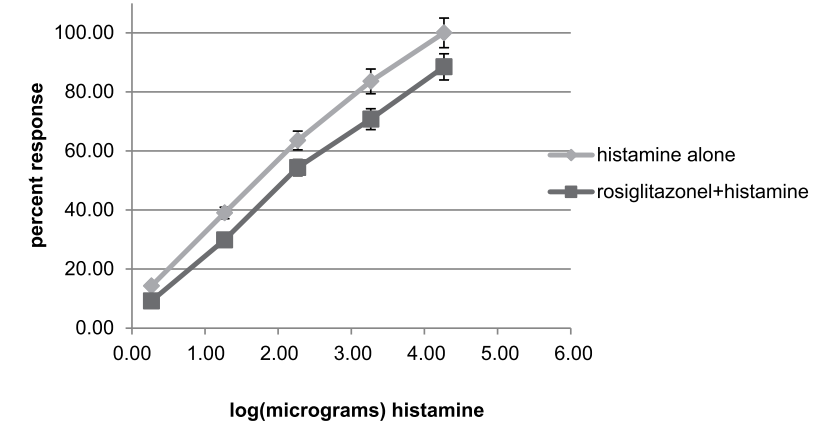

Figure-1. Shows the curve demonstrating the relaxation of the histamine induced contractile response by pretreatment with Rosiglitazone.

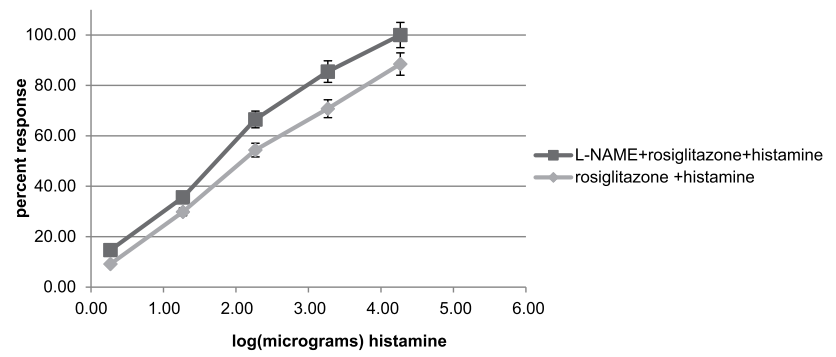

Figure-2a: Shows the comparison between percent response in only Rosiglitazone pretreated group (in blue) and pretreatment with both L-NAME and rosiglitazone (in red).

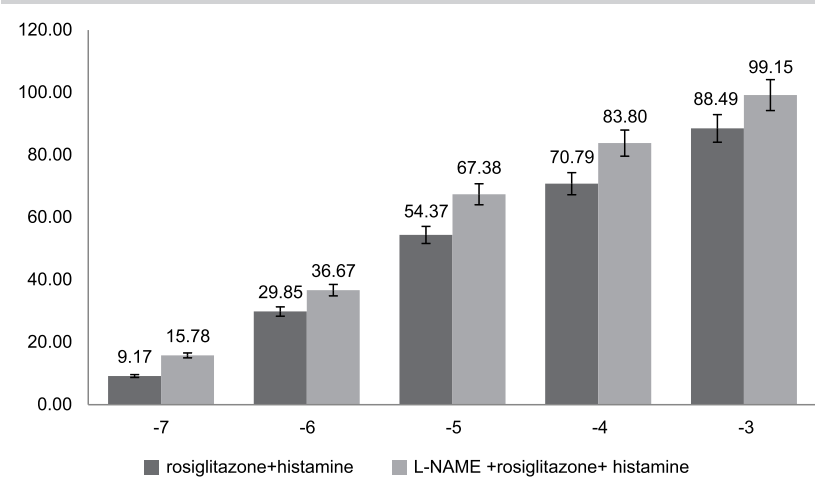

Figure-2b: Bar diagram showing histamine induced contractions after pretreatment with Rosiglitazone and response to histamine after pretreatment with both L-NAME and Rosiglitazone. 


\begin{tabular}{|c|c|c|c|c|c|c|c|c|c|c|c|}
\hline \multirow{3}{*}{$\begin{array}{l}\text { Serial } \\
\text { no. }\end{array}$} & $\begin{array}{c}\text { Gp } \\
3\end{array}$ & Gp & $\begin{array}{c}\text { Gp } \\
3\end{array}$ & $\begin{array}{c}\text { Gp } \\
6\end{array}$ & $\begin{array}{c}\text { Gp } \\
3\end{array}$ & $\begin{array}{c}\text { Gp } \\
6\end{array}$ & \multicolumn{2}{|c|}{ Gp } & $\begin{array}{c}\text { Gp } \\
6\end{array}$ & $\begin{array}{c}\text { Gp } \\
3\end{array}$ & $\begin{array}{c}\text { Gp } \\
6\end{array}$ \\
\hline & \multicolumn{11}{|c|}{ Concentration $(\mu \mathrm{M})$} \\
\hline & $10^{-7}$ & $10^{-7}$ & $10^{-6}$ & $10^{-6}$ & $10^{-5}$ & $10^{-5}$ & $10^{-4}$ & \multirow{2}{*}{$\begin{array}{c}10^{-4} \\
63\end{array}$} & $10^{-3}$ & \multicolumn{2}{|r|}{$10^{-3}$} \\
\hline 1 & 7 & 11 & 20 & 31 & 41 & 50 & 57 & & 68 & \multicolumn{2}{|r|}{78} \\
\hline 2 & 8 & 10 & 25 & 30 & 42 & 49 & 55 & 66 & 70 & \multicolumn{2}{|r|}{75} \\
\hline 3 & 6 & 12 & 23 & 29 & 39 & 53 & 55 & 65 & 66 & \multicolumn{2}{|r|}{77} \\
\hline 4 & 7 & 14 & 25 & 28 & 43 & 52 & 56 & 68 & 71 & \multicolumn{2}{|r|}{78} \\
\hline 5 & 7 & 15 & 20 & 28 & 45 & 55 & 53 & 65 & 68 & \multicolumn{2}{|r|}{76} \\
\hline 6 & 8 & 12 & 27 & 26 & 45 & 57 & 56 & 66 & 72 & \multicolumn{2}{|r|}{81} \\
\hline Mean & 7.17 & 12.33 & 23.33 & 28.67 & 42.5 & 52.67 & 55.33 & 65.5 & 69.17 & \multicolumn{2}{|r|}{77.5} \\
\hline SD & 0.75 & 1.86 & 2.87 & 1.75 & 2.34 & 3.01 & 1.37 & 1.64 & 2.23 & \multicolumn{2}{|r|}{2.07} \\
\hline SEM & 0.31 & 0.76 & 1.17 & 0.71 & 0.96 & 1.23 & 0.56 & 0.67 & 0.91 & \multicolumn{2}{|r|}{0.85} \\
\hline$P$ value & \multicolumn{2}{|c|}{ 0.000* } & \multicolumn{2}{|c|}{$0.117^{\star}$} & \multicolumn{2}{|c|}{ 0.000* } & \multicolumn{2}{|c|}{$0.000 *$} & \multicolumn{3}{|c|}{$0.000^{*}$} \\
\hline \multicolumn{12}{|c|}{$\begin{array}{l}\text { Table-I. Comparison among groups of the responses of the pig tracheal muscle. } \\
\qquad \text { P-value }>0.05=\text { Not significant (Ns) }\end{array}$} \\
\hline \multirow{2}{*}{\multicolumn{4}{|c|}{ Concentration of Histamine (M) }} & \multicolumn{5}{|c|}{ Percent Contraction (\%) } & \multirow{2}{*}{\multicolumn{3}{|c|}{ Percent Deviation (\%) }} \\
\hline & & & & \multicolumn{3}{|c|}{ Group 3} & & Group 6 & & & \\
\hline $10^{-7}$ & & & & & 9.17 & & & 15.78 & & 53 & \\
\hline $10^{-6}$ & & & & & 29.8 & & & 36.67 & & 20.51 & \\
\hline $10^{-5}$ & & & & & 54.3 & & & 67.38 & & 21.36 & \\
\hline $10^{-4}$ & & & & & 70.7 & & & 83.80 & & 20.48 & \\
\hline $10^{-3}$ & & & & & 88.4 & & & 99.15 & & 11.36 & \\
\hline
\end{tabular}

\section{DISCUSSION}

Rosiglitazone, whenadded beforeeliciting tracheal contraction with histamine, leads to decrease in the percent contraction. Adding the inhibitor of NO synthesis, L-NAME to the incubation medium for a period of 30 minutes significantly reduced the relaxant effect of rosiglitazone on the histamine induced contractions (Figure-1). Rosiglitazone induced relaxation has been previously observed in isolated tracheal muscle of rats pre-contracted with carbachol. ${ }^{34}$ However, the mechanism of the tracheal relaxation caused by the agonist of PPAR-YY is not completely understood. It has been suggested that PPAR- $\gamma$ stimulated NO release activates signaling in the renal cortex of pre-hypertensive rats after pioglitazone treatment. ${ }^{33}$ The relaxation in contractile response of tracheal muscle in the presence of L-NAME can be explained on the basis of involvement of NO in the relaxing effect of rosiglitazone on airway smooth muscle. NO is produced through a variety of isoforms of the enzyme NO synthase (NOS). These enzymes use amino acid i.e L-arginine, oxygen as well as NADPH as substrates for the production of $\mathrm{NO}$ and L-citrulline. The various forms of NO show an inhibitory non adrenergic as well as non cholinergic action within the neurons, the endothelium and epithelium. On the other hand the pro inflammatory cytokines secrete inducible NOS (iNOS) that is found in macrophages as well as epithelial cells. ${ }^{35}$ The cholinergic neurotransmission may be interfered with because of the released nitric oxide either by the functional antagonism on smooth muscle of the airway or through inhibiting the acetylcholine release via the cholinergic nerve terminals. Through the phosphorylation of eNOS, NO takes part in the cardio-protective activity of the agonists of PPAR- $\gamma$, rosiglitazone. ${ }^{36,37}$ The restoration of the vascular dysfunction by rosiglitazone takes place through the up-regulation of the NO system in the endothelium, as shown in the fructose-fed rat model. ${ }^{38} \mathrm{~A}$ study illustrated the role of $\mathrm{NO}$ in the activity of pioglitazone on the spatial recognition memory. ${ }^{39}$ Similar role of NO maybe present in the airways. Our study hypothesizes that NO is 
involved in the effect of the thiazolidinediones on the airways. In accordance to our findings, a study conducted in pioglitazone improved endothelial function through an increase in nitric oxide bioavailability and partly a decrease in oxidative stress after administration of pioglitazone. ${ }^{33}$ Studies suggest that activation of the PPAR-y receptor can influence and change the expression of signaling molecules of the insulin signaling cascade (IRS, PI3K, Akt, eNOS, 5-AMP kinase, GLUT4, etc.) connected with improvement of insulin sensitivity and/or endothelial dysfunction. ${ }^{40}$ Similar mechanism may be involved in the airways. Additional studies are required in order to establish the role of NO in the relaxant activity of the rosiglitazone. This study basically focuses on the larger airways and so the action of these drugs on the smaller airway muscles is to be elucidated. In addition it has been demonstrated through various studies that most of the peripheral smaller airways have a much less contribution the total airflow resistance as compared the large airways ${ }^{41,42,43}$ thus making large airways an important target of agonists.

\section{CONCLUSION}

The results of this study are suggestive that the rosiglitazone induced relaxation on the trachea contracted via histamine is in part through the synthesis and release of NO, thus indicating the possible influence of cGMP pathway mediating the action of $\mathrm{NO}$ in the regulation of airway smooth muscle tone.

Copyright@ 25 Jan, 2020.

\section{REFERENCES}

1. Adeloye D, Chua S, Lee C, Basquill C, Papana A, Theodoratou E, Nair H, Gasevic D, Sridhar D, Campbell $H$, Chan KY. Global and regional estimates of COPD prevalence: Systematic review and meta-analysis. Journal of global health. 2015 Dec; 5(2).

2. YkRizos CV, Kei A, Elisaf MS. The current role of thiazolidinediones in diabetes management. Archives of toxicology. 2016 Aug 1; 90(8):1861-81.

3. Kaur J. A comprehensive review on metabolic syndrome. Cardiology research and practice. 2014; 2014.
4. Lecca D, Nevin DK, Mulas G, Casu MA, Diana A, Rossi D, Sacchetti G, Carta AR. Neuroprotective and anti-inflammatory properties of a novel nonthiazolidinedione PPARy agonist in vitro and in MPTP-treated mice. Neuroscience. 2015 Aug 27; 302:23-35.

5. Carta AR \& Simuni T. Thiazolidinediones under preclinical and early clinical development for the treatment of Parkinson's disease. Expert Opin Investig Drugs 2015; 24(2): 219-27.

6. Musso G, Cassader M, Paschetta E, Gambino R. Thiazolidinediones and Advanced Liver Fibrosis in Nonalcoholic Steatohepatitis: A Meta-analysis. JAMA Intern Med 2017; 177(5): 633-40.

7. Scheen AJ, Esser N and Paquot N. Antidiabetic agents: Potential anti-inflammatory activity beyond glucose control. Diabetes Metab 2015; 41 (3): 183-94.

8. Chou PS, LinHo B and HanYang Y. Effects of pioglitazone on the incidence of dementia in patients with diabetes. J Diabetes Complications 2017; 31(6): 1053-57.

9. Rinne ST, Liu CF, Feemster LC, Collins BF, Bryson $\mathrm{CL}$, O'Riordan TG, and HAu D. Thiazolidinediones are associated with a reduced risk of COPD exacerbations. Int J Chron Obstruct Pulmon Dis 2015; 10: 1591-97.

10. Banno A, Reddy AT, Lakshmi SP, Reddy RC. PPARs: key regulators of airway inflammation and potential therapeutic targets in asthma. Nuclear receptor research. 2018;5.

11. El-Naa MM, El-Refaei MF, Nasif WA, Abduljawad SH, El-Brairy Al, El-Readi MZ. In-vivo antioxidant and antiinflammatory activity of rosiglitazone, a peroxisome proliferator-activated receptor-gamma (PPAR-y) agonists in animal model of bronchial asthma. Journal of Pharmacy and Pharmacology. 2015 Oct; $67(10): 1421-30$.

12. Zhao $Y$, Huang $Y$, He J, Li C, Deng W, Ran X, Wang D. Rosiglitazone, a peroxisome proliferator-activated receptor-y agonist, attenuates airway inflammation by inhibiting the proliferation of effector $T$ cells in a murine model of neutrophilic asthma. Immunology letters. 2014 Jan 1; 157(1-2):9-15.

13. Lakshmi SP, Reddy AT, Banno A, Reddy RC. PPAR agonists for the prevention and treatment of lung cancer. PPAR research. 2017 Feb 20;2017. 
14. Basu-Roy U, Han E, Rattanakorn K, Gadi A, Verma $\mathrm{N}$, Maurizi $\mathrm{G}$, et al. PPARy agonists promote differentiation of cancer stem cells by restraining YAP transcriptional activity. Oncotarget 2016; 7(38): 60954-970.

15. Yeligar SM, Harris FL, Brown LS, Hart CM. B32 Regulation of inflammation and lung injury I: Peroxisome Proliferator-Activated Receptor Gamma Activation With Pioglitazone Attenuates AlcoholInduced Alveolar Macrophage Nox4 Expression And Phagocytic Dysfunction Via Mir-92a/b Up-Regulation. American Journal of Respiratory and Critical Care Medicine. 2015; 191:1.

16. Lakshmi SP, Reddy AT, Banno A and Reddy RC. Airway Epithelial Cell Peroxisome Proliferator-Activated Receptor Y Regulates Inflammation and Mucin Expression in Allergic Airway Disease. J Immunol 2018; $201(6)$ : 1775-83.

17. El-Naa MM, El-Refaei MF, Nasif WA, Abduljawad $\mathrm{SH}$, and El-Brairy Al. In-vivo antioxidant and antiinflammatory activity of rosiglitazone, a peroxisome proliferator-activated receptor-gamma (PPAR-y) agonists in animal model of bronchial asthma. $J$ Pharm Pharmacol 2015; 67(10): 1421-30.

18. Cheng Y, Li S, Wang M, Cheng C, Liu R. Peroxisome Proliferator Activated Receptor gamma (PPARY) Agonist Rosiglitazone Ameliorate Airway Inflammation by Inhibiting Toll-Like Receptor 2 (TLR2)/Nod-Like Receptor with Pyrin Domain Containing 3 (NLRP3) Inflammatory Corpuscle Activation in Asthmatic Mice. Medical Science Monitor. 2018 Dec 13; 24:9045-53.

19. Lakshmi SP, Reddy AT, Zhang Y, Sciurba FC, Mallampalli RK, Duncan SR, Reddy RC. Down-regulated peroxisome proliferator-activated receptor Y (PPARY) in lung epithelial cells promotes a PPARy agonistreversible proinflammatory phenotype in chronic obstructive pulmonary disease (COPD). Journal of Biological Chemistry. 2014 Mar 7; 289(10):6383-93.

20. Reddy TA, Lakshmi SP, Banno A and Reddy RC. Role of GPx3 in PPARy-induced protection against COPDassociated oxidative stress. Free Radic Biol Medic 2018; 126: 350-57, 2018.

21. Lea S, Plumb J, Metcalfe H, Spicer D, Woodman P, Fox $\mathrm{JC}$ and Singh D. The effect of peroxisome proliferatoractivated receptor-c ligands on in vitro and in vivo models of COPD. Eur Resp J 2014; 43: 409-20.

22. Bourke JE, Bai Y, Donovan C, Esposito JG, Tan X, Sanderson MJ. Novel small airway bronchodilator responses to rosiglitazone in mouse lung slices. American journal of respiratory cell and molecular biology. 2014 Apr; 50(4):748-56.
23. Lee HY, Rhee CK, Kang JY, Park CK, Lee SY, Kwon SS, Kim YK, Yoon HK. Effect of intranasal rosiglitazone on airway inflammation and remodeling in a murine model of chronic asthma. The Korean journal of internal medicine. 2016 Jan; 31(1):89.

24. Xu J, Zhu YT, Wang GZ, Han D, Wu YY, Zhang DX, et al. The PPARY agonist, rosiglitazone, attenuates airway inflammation and remodeling via heme oxygenase-1 in murine model of asthma. Acta Pharmacol Sin 2015; 36: 171-78.

25. Meng X, Sun X, Zhang Y, Shi H, Deng W, Liu Y, et al. PPARy Agonist PGZ Attenuates OVA-Induced Airway Inflammation and Airway Remodeling via RGS4 Signaling in Mouse Model. Inflammation 2018; 41(6): 2079-89.

26. Castro PF, de Andrade DL, Reis CD, Costa SH, Batista $A C$, da Silva RS, Rocha ML. Relaxing effect of a new ruthenium complex nitric oxide donor on airway smooth muscle of an experimental model of asthma in rats. Clinical and Experimental Pharmacology and Physiology. 2016 Feb; 43(2):221-9.

27. Insuela DB, Daleprane JB, Coelho LP, Silva AR, e Silva PM, Martins MA, Carvalho VF. Glucagon induces airway smooth muscle relaxation by nitric oxide and prostaglandin E2. Journal of Endocrinology. 2015 Jun $1 ; 225(3): 205-17$.

28. Malinovschi A, Janson C, Borres $M$, Alving $K$. Simultaneously increased fraction of exhaled nitric oxide levels and blood eosinophil counts relate to increased asthma morbidity. Journal of Allergy and Clinical Immunology. 2016 Nov 1;138(5):1301-8.

29. Insuela DBR, Daleprane JB, Coelho LP, Silva AR, Re Silva PM, Martins MA and Carvalho VF. Glucagon induces airway smooth muscle relaxation by nitric oxide and prostaglandin E2. J Endocrinol 2015; 25(3): 205-17.

30. Raffay TM, Dylag AM, Di Fiore JM, Smith LA, Einisman $\mathrm{HJ}$, Li Y, et al. S-Nitrosoglutathione Attenuates Airway Hyperresponsiveness in Murine Bronchopulmonary Dysplasia. Mol Pharmacol 2016; 90(4):418-26.

31. Bi R, Bao C, Jiang L, Liu H, Yang Y, Mei J, Ding F. MicroRNA-27b plays a role in pulmonary arterial hypertension by modulating peroxisome proliferatoractivated receptor Y dependent Hsp90-eNOS signaling and nitric oxide production. Biochemical and biophysical research communications. 2015 May 1;460(2):469-75. 
32. Wang Y, Zhao X, Lotz M, Terkeltaub R, Liu $\square$ Bryan R. Mitochondrial biogenesis is impaired in osteoarthritis chondrocytes but reversible via peroxisome proliferator-activated receptor y coactivator $1 \mathrm{a}$. Arthritis \& rheumatology. 2015 May; 67(8):2141-53.

33. Kvandova M, Barancik M, Balis $P$, Puzserova A, Majzunova $M$ and Dovinova I. The peroxisome proliferator-activated receptor gamma agonist pioglitazone improves nitric oxide availability, reninangiotensin system and aberrant redox regulation in the kidney of pre-hypertensive rats. J Physiol Pharmacol 2018; 69(2): 231-43.

34. Donovan C, Bailey SR, Tran J, Haitsma G, Ibrahim ZA, Foster SR, Tang ML, Royce SG and Bourke JE. Rosiglitazone elicits in vitro relaxation in airways and precision cut lung slices from a mouse model of chronic allergic airways disease. Am J Physiol Lung Cell Mol Physiol 2015; 309(10): L1219-28.

35. Zeng $\mathrm{H}$, Belser JA, Goldsmith CS, Gustin KM, Veguilla V, Katz JM, Tumpey TM. A (H7N9) virus results in early induction of proinflammatory cytokine responses in both human lung epithelial and endothelial cells and shows increased human adaption compared with avian H5N1 virus. Journal of virology. 2015 Feb 11:JVI03095.

36. Gonon AT, Bulhak A, Labruto F, Sjöquist PO, Pernow J. Cardioprotection mediated by rosiglitazone, a peroxisome proliferatoractivated receptor gamma ligand, in relation to nitric oxide. Basic research in cardiology. 2007 Jan 1;102(1):80-9.
37. Kvandová M, Majzúnová M and Dovinová I. The role of PPARy in cardiovascular diseases. Physiol Res 2016; 65(Suppl. 3): S343-63.

38. St-Pierre P, Bouffard L and Maheux P. Rosiglitazone increases extravasation of macromolecules and endothelial nitric oxide synthase in skeletal muscles of the fructose-fed rat model. Biochem Pharmacol 2004; 67(10): 1997-2004.

39. Allami N, Javadi-Paydar M, Rayatnia F, Sehhat K, Rahimian R, Norouzi A, et al. Suppression of nitric oxide synthesis by L-NAME reverses the beneficial effects of pioglitazone on scopolamine-induced memory impairment in mice. Eur $\mathrm{J}$ Pharmacol 2011; 650(1): 240-48.

40. Hidaka T, Nakagawa K, Goto C, Soga J, Fujii Y, Hata T, et al. Pioglitazone improves endothelium-dependent vasodilation in hypertensive patients with impaired glucose tolerance in part through a decrease in oxidative stress. Atherosclerosis 2010; 210(2): 521-24.

41. J. C. Hogg. Pathophysiology of airflow limitation in chronic obstructive disease. Lancet 2004; 364: 98596.

42. WR Roche. Inflammatory and structural changes in the small airways in bronchial asthma," Am J Resp Crit Care Med 1998; 157: S191-94.

43. King GG, Downie SR, Vernbanck S, Thorpe CW, Berend N, Salome CM and Thompson B. Effects of methacholine on small airway function measured by forced oscillation technique and multiple breath nitrogen washout in normal subjects. Respir Physiol Neurobiol 2005; 148: 165-77.

\begin{tabular}{|c|c|c|c|}
\hline \multicolumn{4}{|c|}{ AUTHORSHIP AND CONTRIBUTION DECLARATION } \\
\hline Sr. \# & Author(s) Full Name & Contribution to the paper & Author(s) Signature \\
\hline 1 & Naila Abrar & Topic, Lab work, write up. & \\
\hline 2 & Ayesha Janjua & Topic, Lab work, Write up. & \\
\hline 3 & Sarwat Jahan & Write up. & \\
\hline 4 & Zarafshan Badar & Write up. & \\
\hline 5 & Asma Khan & Write up. & \\
\hline 6 & Fatima Qasim & Write up. & \\
\hline
\end{tabular}

